\title{
АКТУАЛЬНЫЕ ВОПРОСЫ ИЗУЧЕНИЯ ИСТОРИИ СТАТИСТИЧЕСКИХ КОМИТЕТОВ ЮГА РОССИИ В ХІХ в.
}

В статье рассматривается становление статистического комитета на юге России. Автором анализируется общее и особенное в истории образования статкомитетов, изучаются профессиональные контакты различных статистических комитетов, исследуется место статкомитетов в общей управленческой вертикали органов государственной статистики, проводится сравнение с научно-историческими обществами, утверждается, что местные статкомитеты исполнили функции губернских ученых архивных комиссий. В рамках данного исследования предпринята попытка в общих чертах осветить процесс создания таких статкомитетов, попытавшись выявить причины подобного положения вещей. Автором разработана проблема формирования архивов при местных статистических комитетах, эти архивы пополнялись как текущими документами статкометов, так и историческими документами, поступавшими туда от частных лиц, а также входит целенаправленный поисковый работы со стороны самих статкомитетов. Отмечается, что изучение архива донского областного статскомитета в целом помогает лучше уяснить не только методику сбора исторических документов на дому, но фрактическое их перемещение по разным местам хранения, а также установить новые фракты по истории архивного дела на
Дону XIX в. Автором отслеживается местная специфика организации комитетов по примеру других губерний. В деле создания новых статкомитетов или преобразования старых - в новые. Отмечается, что в 1861 г. Кубанском и Терском казачьих войсках были утверждены должности по части статистики. Другой аспект местной специфики состоял в необходимости учитывать контекст отношений с местными народами, во многом испытавшими на себе события и последствия кавказской войны. В статье автор пытается установить внутренние закономерности в хронологии деятельности статкомитетов казачьих регионов. В заключении утверждается, что губернские статкомитеты с 1860x гг., а позже ученые архивные комиссии создали оригинальную научную гуманитарную инфраструктуру страны, живой организм исторической науки. Статкомитеты по ряду показателей превзошли краеведческий уровень организации исследовательских подходов к организации, став центрами местной интеллигенции, независимо от своей профессиональной деятельности и социального статуса.

Ключевые слова: статический комитет, провинциальная историческая наука, научные исторические общества, архивные комиссии, гуманитарная инфраструктура страны.

E. R. Rubinina

\section{TOPICAL ISSUES OF STUDYING THE HISTORY OF STATISTICAL COMMITTEES OF THE SOUTH OF RUSSIA IN THE XIX CENTURY}

The article studies the formation of a statistical committee in the south of Russia. The general and the special in the history of education of statistical committees are analyzed, the professional contacts of various statistical committees are studied, the place of statistical committees in the general managerial vertical of state statistics bodies is examined. A comparison is made with scientific and historical societies, it is stated that the local statistical committees fulfilled the functions of provincial scholars of archival commissions. The author attempts to outline the process of establishing such statistical committees, trying to reveal the reasons for this state of affairs. The author develops the problem of forming archives with local statistical committees, the archives were replenished with current documents of statistical files, as well as with historical documents received from private individuals, and also includes targeted search work on the part of the statistical committees themselves. It is noted that the study of the archive of the Don regional statistical committee as a whole helps to better understand not only the method of collecting historical documents at home, but actually move them to different storage locations, as well as establish new facts on the history of archive business in the nineteenth century. The author traces the local specifics of organizing committees by the example of other provinces. The establishment of new statis- 
tical committees or conversion of old ones into new ones is studied. It is noted that in 1861, Kuban and Terek Cossack troops were approved posts on statistics. Another aspect of local specifics was the need to take into account the context of relations with local peoples that in many respects experienced the events and consequences of the Caucasian war. The author tries to establish internal regularities in the chronology of the activity of the statistical committees of the Cossack regions. In conclusion, it is asserted that since the 1860 s the provincial statistical

История статистических комитетов в казачьих областях (регионах) Северного Кавказа, а шире - Юга России [10, с. 141] - должна рассматриваться не только в контексте истории статистики и формирования органов государственной статистики. Перед нами пространство более широких исследовательских проблем, среди которых: общее и особенное в истории образования статкомитетов на территории казачьих Войск Юга России и других территорий указанного региона; профрессиональные контакты представителей разных статкомитетов на Юге России, выявление вклада местных статкомитетов в историю становления и развития архивного дела, провинциальной исторической науки, сохранения историко-культурного наследия и т.п. Интересна проблема места статкомитетов на Юге России в общей управленческой вертикали органов государственной статистики - поскольку, например, ТОСК подчинялся не только Центральному статкомитету, но и Кавказскому областному статистическому комитету.

Актуальна также другая исследовательская проблема - о сравнении статкомитетов с научно-историческими обществами, пик образования которых тоже приходится на вторую половину XIX в. [11, с. 38-54]. В указанной связи необходимо сказать о том, что местные статкомитеты, по сути, исполнили функции, например, губернских ученых архивных комиссий. Немаловажно определить место статистических комитетов среди других учреждений науки и культуры, в т.ч. научных обществ [4, c.118-121]. Например, деятельность местных статкомитетов выделяется на фоне того, что на всем Северном Кавказе губернская ученая архивная комиссия была создана только в Ставропольской губернии (1908 г.), а всевозможные «Общества любителей изучения...» созданы были позже многих статкомитетов, с включением в свой состав многих представителей из состава все тех же... статистических комитетов. committees, and later the academic archival commissions - created the original scientific humanitarian infrastructure of the country, the living organism of historical science. The statistical committees on a number of indicators have surpassed the regional study of research approaches to the organization, becoming centers of local intelligentsia, regardless of their professional activities and social status.

Key words: static committee, provincial historical science, scientific historical societies, archival commissions, humanitarian infrastructure of the country.

Не подлежит сомнению, что именно местные статкомитеты взяли на себя фрунции главных учреждений научного характера, не подменив, а заменив, в силу региональной специфики, многие другие аналогичные учреждения, существовавшие в России XIX - начале XX вв. При этом, верно отмечает М. Е. Колесникова, имелось, как минимум, одно существенное отличие в деятельности статкомитетов от научных обществ России: их «формами работы... были не регулярные заседания и обсуждение докладов, хотя такие и проводились, а индивидуальная творческая деятельность» [4, с. 119]. Другое дело, что утверждение программ работ статкомитетов и другие важные решения все же принимались на заседаниях статкомитетов: поэтому анализ сохранившихся протоколов таких заседаний может иметь существенное значение при изучении в динамике научно-исследовательской и иной деятельности местных статкомитетов. Кроме того, на заседания часто выносили на обсуждение подготовленные его членами материалы, которые предполагалось опубликовать и анализ которых позволяет лучше уяснить внутреннюю ситуацию в комитетах, постараться проникнуть в атмосфреру научного поиска местных интеллектуалов.

Можно согласиться с мнением В. А. Бердинских о том, что губернские статкомитеты с 1860-х гг., а позже - ученые архивные комиссии - создали оригинальную научную гуманитарную инфраструктуру страны, живой организм исторической науки». Превзойдя по ряду показателей краеведческий (любительский) уровень организации исследовательских подходов к своей работе, статкомитеты объективно должны были стать центрами местной интеллигенции, независимо от своей профессиональной деятельности и социального статуса. Такой статус они вряд ли обрели бы, опираясь только на административный ресурс войсковых или губернских властей. На повестке дня, следовательно, еще один актуальный 
вопрос - о принципах и формах внутренней, неофициальной, самоорганизации участников этого типа организаций, о «социальных сетях» членов статкомитетов, об их профессиональной коммуникации с представителями исторических, а также научно-исторических обществ. Статкомитеты сумели развернуть горизонтальную структуру связей друг с другом и обмена опытом. И дело было в том, как верно отмечает В. А. Бердинских, что «проблемы одного статкомитета... были очень типичны для всех других. Вдобавок многие из этих проблем они могли решить, лишь координируя свои действия» [4, с. 141]. Более того, совпадал, по сути, объект изучения для статкомитетов в великорусских губерниях, чего, кстати, нельзя сказать об объекте (-ах) изучения анализируемых нами статкомитетах Юга России. Мы считаем, что именно неформальное отношение членов статкомитетов Юга России (вероятно, это общая тенденция) к выполнению т.н. «необязательных» статработ, и привело в итоге к созданию оригинальной профессиональной среды, позволившей местным статкомитетам развиваться как учреждениям научно-исследовательского характера, успешно избегавшим назойливого администрирования со стороны властей. «Постепенно необязательные работы настолько заинтересовали членов комитета, что едва ли не заслонили все остальные возложенные на них функции. Многие из них участвовали в экспедициях, исследующих различные населенные пункты области, собирали экспонаты для этнографического и естественноисторического музея, готовили для изданий комитета научные статьи» [10, с. 37].

С вопросом о неформальных способах организации местными статкомитетами своей работы тесно связан еще один существенный исследовательский вопрос - о роли секретарей статкомитетов как важного организующего начала в жизни статкомитетов, с увлеченной работой который иногда можно оправданно связать даже историю того или иного статкомитета в целом и даже его периодизацию. Например, новый этап в жизни Терского областного статкомитета, несомненно, начался с назначением его секретарем Е. Д. Максимова в 1889 г. Укажем, что через несколько лет после открытия ТОСК численность его действительных членов сократилась примерно на $70 \%$. И ситуация изменилась именно с приходом Е. Д. Максимова, сумевшего наладить и издательскую деятельность, и сбор необходимых статданных на территории Терской области. Первого секретаря Кубанского областного статкомитета, Е. Д. Фелицына, за его преданность делу и огромную работоспособность в КОСК, современники оправданно называли «главной рабочей пружиной в комитете» [2, с. 16]. Именно Е. Д. Фелицын внес основополагающий вклад в создание археологического и этнографического музея - сначала при статкомитете, а затем, с 1879 г. - уже как войскового этнографического и естественно-исторического музея, одного из старейших музеев на всем Северном Кавказе. Личными трудами он наладил систематическое археологическое исследование Кубани и пр. Именно он организовал дело административной статистики на Кубани, «сумел привлечь в работе в комитет почти все наличные местные научные и литературные силы, и таким образом создал серьезный печатный орган» [2, с. 168] - «Кубанский сборник». Секретарь Астраханского губернского статкомитета М.С. Рыбушкин внес заметный личный вклад в развитие не только программы научных исследований комитета, но и местной периодической печати. Он даже разработал программу деятельности «Астраханских губернских ведомостей», которая потом успешно реализовывалась в губернии на протяжении десятилетий [6, с. 16]. Несомненная активизация в деятельности Ставропольского статкомитета связана почти напрямую с деятельностью его членов-секретарей П. П. Соколова, Черноярского и И. В. Бентковского [2, с. 615]. На А. А. Попова, секретаря Новочеркасского статкомитета, легла основная тяжесть инициативной работы по составлению программы работы НСК. Несмотря на отсутствие внушительных к 1860-м гг. результатов, именно лидерские качества А. А. Попова привели в итоге к превращению комитета в подобие малой донской «академии наук», что дало мощный толчок дальнейшим исследованиям Донской земли [5, с. 56]. В. А. Бердинских говорит даже о секретаре статкомитета, как о типе лидера среди местных интеллектуалов, обладающем глубоко нравственным отношением к своему делу [5, с. 211]. Распространение такого лидерского типа стало возможным после принятия «Положения» 1860 г., когда конкретизировались и повысились требования к кандидату на эту должность, к слову сказать, подчинявшегося только главе губернской канцелярии. Отмечено, что виднейшие и наиболее заметные секретари наиболее активных статкомитетов сами были не только отличными организаторами, но и яркими личностями, выдающимися историками, археологами и этнографрами родного края [5, с. 213]. При этом положение секретарей от- 
личалось противоречивыми чертами: с одной стороны, они сами могли определять круг своих научных занятий, с другой - заметной здесь была профессиональная «текучка»: в отдельные годы второй половины XIX в. - указанную должность оставляли до 50 \% секретарей статкомитетов [1, с. 43].

Почти не разработана в науке проблема формирования архивов при местных статистических комитетах, в т.ч. как источников об их истории, а также об истории, археологии и этнографии тех регионов, на которых комитеты осуществляли свою деятельность. С одной стороны, видно, что архивы статистических столов или отделений передавались статкомитетам - как например, при образовании Терского областного статкомитета. Но потом эти архивы пополнялись как текущими документами самих статкомитетов, так и историческими документами, поступавшими туда от частных лиц, а также в ходе целенаправленной поисковой работы со стороны самих статкомитетов. Следовательно, эта проблема органично вписывается в историю архивов и архивного дела на Юге России и в казачьих войсках. Так, А. М. Савельев, назначенный в 1863 г. правителем дел в ДОСК, одним из первых приступил к работе с бумагами и документами, переданными в комитет из Межевой комиссии в количестве 10 связок. А. М. Савельев сделал доклад на тему исторических актов, среди которых он нашел черновую опись актам и запискам, собранным в архивах: донском, крепости св. Дмитрия Ростовского, азовском, таганрогском, крепости Новохеперской и в астраханском архиве [8, с. 11]. Опись содержит не только заглавие, но и содержание исторических документов, начиная с 1646 г. до начала XIX в. Составителем описи, предположительно, являлся В. Д. Сухоруков: согласно чернового рапорта, найденного там же в связках, дела были переданы именно им Кушнареву, Кучерову и Поснову «для составления исторического описания Войска Донского. Куда же потом перешли эти акты, неизвестно [8, с. 13]. Анализ содержания документов свидетельствует об их важности при изучении станичного управления XVIII в., истории раскола на Дону, падения власти войскового круга, усиления власти старшин и пр. Опись была опубликована по частям в неофициальной части «Донских областных ведомостей» [9, с. 334-339]. При этом члены комитета целенаправленно вели работу по расширенному поиску информации о местах хранения документов, связанных с местной историей. Стоит согласиться с мнением О. А. Горобец о связи между результатами архивных подобных изысканий и периодизацией истории издательской деятельности ДОСК. Недаром А. М. Савельев, под редакцией которого вышел первый выпуск «Трудов» ДОСК (1867 г.), понимал, что многое для изучения края даст выявление, описание и изучение письменных и вещественных памятников. Однако, столкнувшись с объективными трудностями по сбору архивного материала и, к тому же, не поддержанный областной войсковой администрацией, Донской статистический комитет сумел издать в 1874 г. второй и последний сборник своих «Трудов». Важно отметить, что изучение архива Донского областного статкомитета в целом помогает лучше уяснить не только методику сбора исторических документов на Дону, но и фрактическое их перемещение по разным местам хранения, определить степень и масштабы возможных утрат, а также установить новые факты из истории архивного дела на Дону XIX в.

История местных статистических комитетов показывает, что причины и хронология их образования не всегда были связаны с введением в действие уже анализировавшихся выше «Положений» 1834 и 1860 гг. Следовательно, на повестке дня вопрос о критериях для выделения этапов в истории статкомитетов на Юге России и соотношении их с общеимперскими процессами в области создания и государственной статистики. Стоит также дополнить верное, по сути, утверждение о том, что «деятельность северокавказских статистических комитетов относится ко второму периоду существования статистических учреждений России, связанному с реорганизацией статистических комитетов и утверждением 26 декабря 1860 г. «Положения»...» [3, с. 54]. В таком случае, наблюдается определенный разрыв между этим и первым периодом в истории других статкомитетов Юна России, имевших свою определенную предысторию как раз в первой половине XIX в. И затем, по формальным основаниям, Ставропольский статкомитет был образован в 1858 г., т.е. до введения в действие известного «Положения» 1860 г.

Кроме того, мы считаем, что местная специсрика все же существовала, причем не во всем можно согласиться с мнением о роли по вопросу «организации комитетов по примеру других губерний, в связи с преобразованиями 1870 г., когда в казачьих областях были введены общие губернские учреждения» [12, c. 96]. Однако, еще за несколько лет до этого случилось другое важное событие: в 1865 г. введено в действие «Положение о губернских 
и областных статистических комитетах» от 26 декабря 1860 г. на территориях иррегулярных войск, согласно мнению Государственного Совета [8, с. 79]. Другое дело, что теперь заметна инициатива не только центральных ведомств в создании новых статкомитетов или преобразовании старых - в новые. Атаманские правления и атаманские войсковые канцелярии тоже развивались со временем, успев накопить определенный опыт сбора и обработки статданных для атаманской отчетности. Неслучайно, что в том же 1865 г. в Кубанском и Терском казачьих войсках были учреждены должности чиновников по части статистики. «Чиновники войсковых правлений должны были заниматься выполнением обязательных статистических работ и сбором материалов для всеподданнейших отчетов. Но это не снижало остроты проблемы, поскольку не решен был основополагающий вопрос - создание нового статистического учреждения в области» [12, с. 38]. Попытка решить этот вопрос, указывает М. Р. Тазиева, уходит корнями еще в начало 1860-х гг., подтверждая наше мнение о местной, сугубо «казачьей» специфике, повлиявшей не невольно «затягивание» в решении указанного вопроса. Другой аспект местной специфики, еще раз подчеркнем, отсутствовавший за пределами Северного Кавказа, состоял в необходимости учитывать контекст отношений с местными народами, во многом испытавшими на себе события и последствия Кавказской войны. Выдающийся кубанский ученый Б. М. Городецкий справедливо писал, что «в только что замиренном крае нельзя было не считаться с существующими среди горцев-мусульман воззрениями. Рискованно было гласным счислением народонаселения возбуждать в склонных к подозрениям горцах ложные опасения и толки о намерении правительства будто бы установить между ними рекрутский набор или причислить их к казачьему сословию. Помимо того, у мусульман не велись метрические книги (или что-либо им подобное), а вся- кие справки о числе родившихся могли быть приняты мусульманами за оскорбительную нескромность, нарушающую святость домашних тайн, особенно при естественном в то время недоверии горцев к новому для них управлению» [2, с. 121].

Необходимо отметить еще одну деталь, которая показывает общность тех условий, в которых уже в 1860-х гг. пришлось функционировать новым статкомитетам по «Положению» от 26 декабря 1860 г. Например, указывает Б. М. Городецкий, деятельность Ставропольского комитета оживилась только к 1866 г. а до этого она выражалась только в канцелярском составлении обычных официальных отчетов и совершенно небольшом количественном составе его членов [2, с. 198]. И только после существенного пополнения его рядов новыми членами как раз к 1866 г. заседания становятся особенно оживленными: расширяется повестка дня заседаний, издаются инструкции по сбору сведений, совершаются поездки по территории губернии, положено начало форсирования библиотеки комитета и пр. [2, с. 199]. И, напротив, с конца 1880-х гг. издательская, например, деятельность того же комитета сокращается, а общие собрания комитета проходят крайне редко, иногда по целым годам не собираясь вовсе. Примерно те же «зигзаги» характерны для деятельности Терского статистического комитета [2, с. 241] - по крайней мере, в течение долгого времени после создания в 1872 г. Следовательно, можно вновь задаться вопросом а насколько целесообразно отказываться от попыток выделять этапы в истории северокавказских (южнороссийских) статистических комитетов, опираясь не только на «очевидную» хронологию, связанную с 1834 и 1860 гг.? Речь, по нашему мнению, идет о необходимости как раз учитывать местную специфику, пытаясь установить внутренние закономерности в хронологии деятельности статкомитетов казачьих регионов.

\section{Источника и литература}

1. Гациский А. С. Очерк статистических съездов в России. Нижний Новгород: Типография губерноского правления, 1875. 298 c.

2. Городецкий Б. М. Статистические учреждения на Северном Кавказе. М.: Светоч, 2001. 678 с.

3. Колесникова М. Е. Северокавказские статистические комитеты в ландшафте научных обществ России // Вестник Северо-Кавказского федерального университета. 2013. №2 (35). С. 245-250.

4. Королев В. Н. Александр Алексеевич Попов (1800-1859) // Человек второго плана в истории. Ростов-на-Дону: РГУ, 1997. Вып.1. С.147-151.

5. Лебедев С. В. Деятельность Астраханского губернского статистического комитета в 1836-1918 гг:: автореф. дисс. ... канд. ист. наук. Астрахань, 2009. 314 с.

6. Лебедев С. В. Создание Астраханского губернского статистического комитета // Гуманитарные исследования. Журнал фундаментальных и прикладных исследований2001. №1. С.136-143. 
7. Попов И. Областной войска Донского статистический комитет в первые годы его существования (Историческая справка) // Сборник Областного войска Донского статистического комитета. Вып.І. Новочеркасск: [б.и.], 1901. C. $268-274$.

8. Полное собрание законов Российской Империи. Собрание 2. T.XL. Отд.1. №42053. СПб.: Типография 2-го Отделения Собственного Е.И.В. Канцелярии, 1867. 498 с.

9. Савельев А. Материалы для истории Войска Донского. Опись актам и запискам, собранным в архивах Донском, крепости Св. Дмитрия, Азовском, Таганрогском, крепости Новохоперской и Астраханском // Донские войсковые ведомости. 1864. №48. С.384-391.

10. Собриевский А. С. Статистика вообще, на Северном Кавказе и в Ставропольской губернии в частности: ее задачи и организация. Ставрополь: Типография наследников Берк, 1905. 413 с.

11. Степанский А. Д. К истории научно-исторических обществ в дореволюционной России // Археографический ежегодник за 1974 г. М.: Наука, 1975. 174 с.

12. Тазиева М. Р. Государственная статистика на Тереке в 1872-1924 гг.: дисс. ... канд. ист. наук. Нальчик, 2011. $351 \mathrm{c}$.

\section{References}

1. Gatsiskij A. S. Ocherk statisticheskikh s»ezdov v Rossii (Essay on statistical congresses in Russia). Nizhnij Novgorod, 1875. 298 p. (In Russian).

2. Gorodetskij B. M. Statisticheskie uchrezhdeniya na Severnom Kavkaze (Statistical agencies in the North Caucasus). Moscow: Svetoch, 2001. 678 p. (In Russian).

3. Kolesnikova M. E. Severokavkazskie statisticheskie komitety v landshafte nauchnykh obshhestv Rossii (North Caucasian Statistical Committees in the Landscape of Russian Scientific Societies) // Vestnik Severo-Kavkazskogo federal'nogo universiteta. 2013. No.2 (35). P. 245-250. (In Russian).

4. Korolev V. N. Aleksandr Alekseevich Popov (1800-1859) (Alexander Popov (1800-1859) // CHelovek vtorogo plana v istorii. Rostov on Don: RSU publ. Issue.1. P.147-151. (In Russian).

5. Lebedev S. V. Deyatel'nost' Astrakhanskogo gubernskogo statisticheskogo komiteta v 1836-1918 gg. (Activity of the Astrakhan Provincial Statistical Committee in 1836-1918): thesis. Astrakhan', 2009. 314 p. (In Russian).

6. Lebedev S. V. Sozdanie Astrakhanskogo gubernskogo statisticheskogo komiteta (The establishment of the Astrakhan Provincial Statistical Committee) // Gumanitarnye issledovaniya. ZHurnal fundamental'nykh i prikladnykh issledovanij. 2001. №1. P. 136-143. (In Russian).

7. Popov I. Oblastnoj vojska Donskogo statisticheskij komitet $v$ pervye gody ego sushhestvovaniya (Istoricheskaya spravka) (Regional troops of the Don statistical committee in the early years of its existence) (Historical reference) // Sbornik Oblastnogo vojska Donskogo statisticheskogo komiteta. Novocherkassk, 1901. Issue I. P. 268-274. (In Russian).

8. Polnoe sobranie zakonov Rossijskoj Imperii (Complete collection of laws of the Russian empire). Sobr.2. St.Petersburg, 1867. Vol.XL. Otd.1. No. 42053. 498 p. (In Russian).

9. Savel'ev A. Materialy dlya istorii Vojska Donskogo. Opis' aktam i zapiskam, sobrannym v arkhivakh Donskom, kreposti Sv. Dmitriya, Azovskom, Taganrogskom, kreposti Novokhoperskoj i Astrakhanskom (Materials on the history of the Don Army. Inventory of acts and notes collected in the archives of Donskoy, the fortress of St. Dimitri, the Azov, Taganrog, the fortress of Novokhopersk and Astrakhan) // Donskie vojskovye vedomosti. 1864. No.48. P. 384-391. (In Russian).

10. Sobrievskij A. S. Statistika voobshhe, na Severnom Kavkaze i v Stavropol'skoj gubernii v chastnosti: ee zadachi i organizatsiya (Statistics in general, in the North Caucasus and Stavropol Province in particular: its tasks and organization). Stavropol', 1905. 413 p. (In Russian).

11. Stepanskij A. D. K istorii nauchno-istoricheskikh obshhestv v dorevolyutsionnoj Rossii (On the history of scientific and historical societies in pre-revolutionary Russia) // Arkheograficheskij ezhegodnik za 1974 g. Moscow, 1975. 174 p. (In Russian).

12. Tazieva M. R. Gosudarstvennaya statistika na Tereke v 1872-1924 gg. (State statistics on the Terek in 1872-1924): thesis. Nal'chik, 2011. 351 p. (In Russian). 